

\title{
Prevalence and Factors Associated with Comorbid Depression and Anxiety Among Older Adults in South-western Nigeria: A Community-Based Study Akinsulore $\mathrm{A}^{* 1,2}$, Adeseiye $\mathrm{OC}^{3}$, Oloniniyi $\mathrm{IO}^{1,2}$, Esimai $\mathrm{OA}^{3,4}$
}

\begin{abstract}
1Department of Mental Health, Faculty of Clinical Sciences, Obafemi Awolowo University, Ile - Ife, Nigeria 2Department of Mental Health, Obafemi Awolowo University Teaching Hospitals Complex, Ile - Ife, Nigeria ${ }^{3}$ Department of Community Health, Faculty of Clinical Sciences, Obafemi Awolowo University, Ile - Ife, Nigeria ${ }^{4}$ Department of Community Health, Obafemi Awolowo University Teaching Hospitals Complex, Ile - Ife, Nigeria
\end{abstract}

*Correspondence: Dr A Akinsulore, Department of Mental Health, Faculty of Clinical Sciences, Obafemi Awolowo University, Ile-Ife, Osun State, Nigeria. E-mail: sanmilore@oauife.edu.ng; ORCID - https://orcid.org/0000-0001-7611-0458.

\begin{abstract}
Background: Depression and anxiety are common mental disorders that frequently occur in the elderly. When they coexist, it is known as comorbid depression and anxiety.

Objective: To assess the prevalence and factors associated with comorbid depression and anxiety symptoms among older adults in western Nigeria.

Methods: This is a community-based, cross-sectional descriptive survey conducted among 328 consenting older adults. The Geriatric Depression Scale-Short Form (GDS-SF) and Generalized Anxiety Disorder-7 (GAD-7) questionnaires were administered to assess depressive and anxiety symptoms. Socio-demographic information was obtained using a separate questionnaire.

Results: The mean age of the participants was 70.1 years (SD =9.2). Sixty per cent of the respondents were females and $58 \%$ were married. The prevalence of comorbid depression and anxiety was $6.0 \%$ (2.4\% in men and $6.6 \%$ in women) and $13 \%$ had depression-only while $19.9 \%$ had anxiety-only. Socio-demographic factors significantly associated with comorbid depression and anxiety included living alone $(p=0.001)$ and being not married $(p=0.028)$. However, only living alone $(\mathrm{p}=0.015, \mathrm{OR}=1.79,95 \% \mathrm{CI}=1.41$ - 25.36) independently predicted comorbid depression and anxiety symptoms among older adults.

Conclusion: Although the prevalence rates of "depression only" and "anxiety only" were higher among older adults, comorbid depression and anxiety was also prevalent in later life and living alone is a significant predictor. Therefore, there is a need to increase the recognition and treatment of comorbid depression and anxiety in older adults.
\end{abstract}

Keywords: Aging, Anxiety, Depression, Comorbid depression and anxiety, Geriatrics, Prevalence.

\section{Introduction}

Globally, the population of older adults has been increasing at an exponential rate and the proportion of this increase in Africa is one of the fastest in the World. [1] In Nigeria, the older adult population, defined as people aged 60 years and above, is increasing, ${ }^{[2,3]}$ from 6.4 million in 2005 
to a projected population of 12 million in 2025 and 26 million by the year 2050. [3] Moreover, between 2012 and 2017, the number of older adults living in Nigeria increased by about 600,000 and they accounted for about $4 \%$ of the total population of 191 million with an estimated growth rate of $2.5 \%$. [4,5] The increase in the proportion of Nigerian older adults aged 60 years and above may be due to improvement in their standard of living and reduction in the mortality rate. ${ }^{[4]}$ One of the challenges of the older adult population is health problems which include non-communicable diseases such as cardiovascular diseases (hypertension), endocrine diseases (diabetes mellitus) and mental disorders (depression and anxiety). ${ }^{[6,7]}$

Among older adults, depression and anxiety are the most common mental disorders (CMDs) and often not recognized in the primary care setting. $[7,8]$ Among the community-dwelling older adults, the prevalence rates of depression ranges from $2.7 \%$ to $53.1 \%{ }^{[9-12]}$ while that of anxiety ranges from $1.2 \%$ to $27.7 \%$. [4, 13, 14] Therefore, these CMDs pose serious public health problems that are associated with grave consequences in terms of excessive mortality, disability and suicide. ${ }^{[9]}$ Depression can impair an older adult's ability to function and enjoy life and can contribute to poor health outcomes and high cost of health care. [15] Conversely, anxiety, in the older adults, has been associated with increased frequency of incontinence and falling, ${ }^{[16]}$ as well as increased general functional impairment or disability. [17]

When depression and anxiety co-exist in the same individual, it is referred to as comorbid depression and anxiety. The prevalence rates of comorbid depression and anxiety have been reported to vary from $4.3 \%$ to $20.5 \%$ among community-dwelling older adults. [4, 18, 19] The older adult suffering from comorbid depression and anxiety have higher severity of functional impairment than those suffering from depression-only or anxiety-only. [17] Comorbid depression and anxiety in the elderly is associated with increased functional impairment, poor quality of life, symptom severity of medical illness and increased likelihood of suicide. [20]

Indeed, there is a need for geriatric screening of depression and anxiety and their comorbidity in the community. Most of the previous studies conducted in Nigeria on mental disorders among the older adults assessed depression [21, 22] and anxiety [7] separately and did not evaluate the effect of comorbid depression and anxiety. There is a dearth of information on the prevalence of comorbid depression and anxiety among community-dwelling older adults in Nigeria. A recent study on loneliness among retirees in the northern part of Nigeria reported the prevalence of comorbid depression and anxiety as $20.5 \%$. [4] Therefore, the present study aimed at determining the prevalence and factors associated with comorbid depression and anxiety symptoms among a sample of the communitydwelling older adult population in Ile-Ife, southwest Nigeria.

\section{Methods}

\section{Study setting}

This study was conducted in Ife Central Local Government Area (LGA) of Ile-Ife. Ile-Ife is an ancient Yoruba city located in Osun State, Southwestern Nigeria. Ife Central LGA has a population of 167,254 people $(84,653$ males and 82, 601 females). Geographically, Ife Central LGA lies on longitude $4{ }^{\circ} 32^{\prime} \mathrm{E}$ and Latitude $7 \circ 33^{\prime} \mathrm{N}$ with an area of $111 \mathrm{~km}^{2}$. This area is made up of 11 wards characterized by streets and settlements. Farming, trading, artisanship and public service are the main occupations of the local inhabitants of Ile-Ife. Ife Central LGA was purposively chosen for this study as it has both urban and rural communities. 


\section{Study design}

The study used a descriptive cross-sectional design.

\section{Sample size determination}

The sample size was determined using the formula for estimating population proportions $\left(n=z^{2} p q / D^{2}\right)$, where " $n$ " is the minimum required sample size, " $\mathrm{z}$ " is the standard normal deviation, usually set at 1.96 and corresponding to $95 \%$ confidence level, and " $p$ " is the proportion of the population with the desired factor (obtained from a previous study). This was taken as $26.3 \%$ of elderly Nigerians with depressive symptoms in Lagos, Nigeria. [22] The sample size was calculated as 297.8 but was increased to 328 (10\% added to make up for possible incomplete data).

\section{Ethical considerations}

Ethical approval for the study was obtained from the Health Research Ethics Committee of the Institute of Public Health, Obafemi Awolowo University, Ile-Ife (IPHOAU/12/692). Permission to conduct the research was also obtained from Ife Central Local Government Authority, Ile-Ife, Nigeria. Written informed consent was obtained from respondents and they were assured of the confidentiality of the information provided.

\section{Subject / Selection of Subjects}

The study was conducted among the elderly in who met the inclusion criteria which included age of 60 years and above and residence within Ife Central LGA in the preceding two years. Individuals within that age group who were critically ill and could not comprehend or respond to questions asked were excluded. The consenting participants were selected using a multi-stage sampling technique from the wards, through streets to households. Forty-one houses were randomly selected from the streets in each ward. At the last stage, an eligible respondent was recruited from one household in a house based on the study criteria. Simple random sampling technique (balloting method) was used to select the respondents when there was more than one eligible respondent. Also, if there were no eligible respondents in the house, another house was chosen from the list of houses in the street. Overall, 41 respondents were selected from each of the selected wards.

Research Instruments: Data were collected using an interviewer-assisted method and standardized scales for measuring depression and anxiety were used to determine comorbid depression and anxiety among the elderly.

Self-designed questionnaire: Socio-demographic parameters were obtained using a questionnaire designed by the researchers. The questionnaire contained questions on age, marital status, religion, the highest level of education, living conditions, family structure, employment status, living unit and length of stay at the current address.

Geriatric Depression Scale: The Geriatric Depression Scale Short Form (GDS-SF) was used to assess depressive symptoms. The GDS-SF is the shorter version of Geriatric Depression Scale Long Form ${ }^{[23]}$ which was developed in 1986 and consisted of 15 questions extracted from the Long Form GDS which had the highest correlation with depressive symptoms in validation studies. [24] It is a brief, 15-item questionnaire in which participants are required to respond with "yes" or "no" about how they felt over the past week. Of the 15 items, 10 indicate the presence of depression when answered positively, while the remaining 5 questions $(1,5,7,11,13)$ indicate depression when answered negatively. Symptom severity value were 0 to 4 (normal), 5 to 8 (mild depression), 9 to11 (moderate depression) and 12 to 15 (severe depression). The GDS-SF and its Yoruba translation have been used in Nigeria by some researchers. [2, 25, 26] Also, it has been validated and used for assessing depressive symptoms among the elderly in both the community and at the primary health care 
setting. At the recommended cut-off score of 5, the pooled sensitivity of GDS-SF was 0.89 and the specificity was 0.77 . [27]

Generalized Anxiety Disorder Scale (GAD-7): The GAD-7 scale was used to assess the presence of anxiety and its severity among respondents. Although it was primarily designed as a screening tool for generalized anxiety disorder, it also assesses three other common anxiety disorders - panic disorder, social anxiety disorder, and post-traumatic stress disorder. [28] This tool has also been validated for measuring anxiety disorders among various groups. [28] The GAD-7 consists of seven questions with response categories of "not at all', "several days," "more than half the days," and "nearly every day" which are scored 0, 1, 2 and 3 respectively. The total scores range from 0 to 21 and symptom severity values are 0 to 4 (minimal), 5 to 9 (mild), 10 to 14 (moderate), and 15 to 21 (severe). ${ }^{[28]} \mathrm{A}$ Nigerian study reported Cronbach's alpha 0.85 as the reliability coefficient for this scale. [29]

For this study, comorbid depression and anxiety was determined when respondents scored above the cut-off score for depression (GDS-SF score $\geq$ $5)$ and anxiety $(G A D \geq 5)$. The respondents were divided into four groups: respondents with no anxiety and depression, respondents with comorbid depression and anxiety, respondents with anxiety only and respondents with depression only.

\section{Data Collection}

The questionnaire was interviewer-administered, where the interviewer read the questionnaire in Yoruba or English languages depending on the preference of the respondent. Five trained research assistants, who were postgraduate students with satisfactory proficiency in English and Yoruba languages, conducted the interview. Before conducting the interview, the assistants were trained on the research instruments and how to interview the participants for a period of two days. The inter-rater reliability, using the
Kappa coefficient, among the research assistants was 0.85 . The research assistants had continuous access to the researcher both physically and through the phone to sort out relevant issues in the course of data collection. Privacy was also ensured during the interview as much as possible. The entire data collection lasted for a period of four weeks.

\section{Data analysis and management}

Data were entered into and analysed using IBMSPSS software 20.0 version. Descriptive statistics such as proportions and frequencies of sociodemographic variables and comorbid depression and anxiety were determined. Bivariate analysis using Chi-Square and Fishers' Exact tests were conducted to determine the association between comorbid depression and anxiety and sociodemographic parameters. The variables that were significantly associated with comorbid depression and anxiety on bivariate analysis were entered into the binary logistic regression model to identify socio-demographic factors that independently predicted comorbid depression and anxiety. All tests were conducted as 2-tailed while the level of statistical significance was set at $\mathrm{p}<0.05$.

\section{Results}

\section{Sociodemographic Characteristics of the respondents}

A total of 328 respondents were recruited but 12 were removed for reasons of incomplete data thus, 316 were eventually analysed giving a response rate of $96.3 \%$. The mean age of the respondents was $70.1 \pm 9.2$ years and $152(48.1 \%)$ were within the 60 to 69 years age group. One hundred and eighty-nine (59.8\%) were females and $182(57.6 \%)$ were married. One hundred and sixty-six (52.5\%) had polygamous family settings; $181(57.3 \%)$ lived with their spouses while 70 (22.1\%) lived alone. Most of the respondents $(96.2 \% ; \mathrm{n}=304)$ were Yoruba and $242(76.6 \%)$ 
were Christians. One hundred and eighty (57.0\%) currently lived in a shared flat while $172(54.4 \%)$ had lived at their current abode for 20 years or less. One hundred and fifty-three $(48.4 \%)$ were self-employed and $129(40.8 \%)$ had no formal education (Table I).

\section{Prevalence of comorbid depression and anxiety,} depression and anxiety

Overall, 193 (61.1\%) had no symptoms of depression or anxiety while the prevalence rate of comorbid depression and anxiety was $6.0 \%$ (19/316) (with 2.4\% among males and 6.6\% among females). The prevalence rates of isolated depressive and anxiety symptoms were $13.0 \%$ (41/316) and 19.9\% (63/316) respectively.

\section{Association between socio-demographic characteristics and comorbid depression and anxiety}

As shown in Table II, a higher proportion of the respondents who were widowed or divorced $(14 \%)$ had comorbid depression and anxiety compared with respondents who were married $(5 \%)$ and the difference was statistically significant $\left(\chi^{2}=4.832, p=0.028\right)$. There was also a significant association between living conditions and comorbid depression and anxiety in the elderly $\left(\chi^{2}=14.829, \mathrm{p}<0.001\right)$; the proportion of the elderly living alone (24\%) with comorbid depression and anxiety was significantly higher than the proportion of the elderly living with people (5\%). There were no significant associations between comorbid depression and anxiety and other sociodemographic parameters.

\section{Predictor of comorbid depressive and anxiety symptoms}

Table III shows that living alone was significantly associated with the presence of comorbid depression and anxiety $(\mathrm{p}=0.015, \mathrm{OR}=1.79,95 \%$ $C I=1.41-25.36)$. This indicated that the older adults that lived alone were about two times more likely to have comorbid depression and anxiety than those living with their family, spouse or relatives.

\section{Discussion}

This study showed that both depression and anxiety were very common among this cohort of community-dwelling elderly. The prevalence rate of comorbid depression and anxiety in the present study is comparable to $8 \%$ reported in a community-based study conducted among elderly subjects aged 90 years in the Netherlands using the GDS-SF and Anxiety Screening Questionnaire. [19]

The finding of this study is also consistent with the results of a Longitudinal Aging Study Amsterdam (LASA) study, which reported that the prevalence rates for co-existing depression and anxiety varied from $4.3 \%$ to $9.5 \%$. [18] However, this observation is different from the findings of Schoevers, et al. [30] that reported a higher prevalence of co-occurring depression and generalized anxiety disorders among elderly patients. Also, a Nigerian study conducted among community-living retirees using Depression Anxiety and Stress Scale reported a higher prevalence of comorbid depression and anxiety. ${ }^{[4]}$

The variation in the prevalence rates observed across studies may be attributed to the differences in methodology concerning the age of the study population, the culture, values and environmental peculiarities. It may also be due to the differences in the instruments used for measuring the depressive and anxiety symptoms. 
Table I: Socio-demographic characteristics and living conditions of the 316 respondents

\begin{tabular}{|c|c|c|}
\hline Parameters & Frequency & Percentage \\
\hline \multicolumn{3}{|l|}{ Age Groups (Years) } \\
\hline $60-69$ & 152 & 48.1 \\
\hline $70-79$ & 101 & 32.0 \\
\hline$\geq 80$ & 63 & 19.9 \\
\hline \multicolumn{3}{|l|}{ Sex } \\
\hline Male & 127 & 40.2 \\
\hline Female & 189 & 59.3 \\
\hline \multicolumn{3}{|l|}{ Marital status } \\
\hline Married & 182 & 57.6 \\
\hline Widowed & 128 & 40.5 \\
\hline Single, Divorced/Separated & 6 & 1.9 \\
\hline \multicolumn{3}{|l|}{ Family structure } \\
\hline Monogamy & 150 & 47.5 \\
\hline Polygamy & 166 & 52.5 \\
\hline \multicolumn{3}{|l|}{ Living condition } \\
\hline Alone & 70 & 22.1 \\
\hline With spouse & 181 & 57.3 \\
\hline With children/grandchildren & 31 & 9.8 \\
\hline With friends/relatives & 34 & 10.8 \\
\hline \multicolumn{3}{|l|}{ Years lived in current residence } \\
\hline$<20$ years & 172 & 54.4 \\
\hline $21-40$ years & 95 & 30.1 \\
\hline$\geq 40$ years & 49 & 15.5 \\
\hline \multicolumn{3}{|l|}{ Ethnicity } \\
\hline Yoruba & 304 & 96.2 \\
\hline Others & 12 & 3.8 \\
\hline \multicolumn{3}{|l|}{ Religion } \\
\hline Christian & 242 & 76.6 \\
\hline Islam & 70 & 22.1 \\
\hline Traditional worshippers & 4 & 1.3 \\
\hline \multicolumn{3}{|l|}{ Level of education } \\
\hline No formal education & 129 & 40.8 \\
\hline Primary & 89 & 28.2 \\
\hline Secondary & 58 & 18.3 \\
\hline Tertiary & 40 & 12.7 \\
\hline \multicolumn{3}{|l|}{ Occupational status } \\
\hline Unemployed & 41 & 13.0 \\
\hline Employed & 74 & 23.4 \\
\hline Self-employed & 153 & 48.4 \\
\hline Retired & 48 & 15.2 \\
\hline \multicolumn{3}{|l|}{ Types of housing unit } \\
\hline Single room apartment & 62 & 19.6 \\
\hline Shared flat & 180 & 57.0 \\
\hline Others & 74 & 23.4 \\
\hline
\end{tabular}


Table II: Association between sociodemographic characteristics and comorbid depression and anxiety

\begin{tabular}{|c|c|c|c|c|}
\hline Characteristics & $\begin{array}{l}\text { Comorbid } \\
\text { depression and } \\
\text { anxiety } \\
n=19\end{array}$ & $\begin{array}{l}\text { No anxiety and no } \\
\text { depression } \\
n=193\end{array}$ & $\begin{array}{l}\text { Total } \\
n=212\end{array}$ & Statistics \\
\hline \multicolumn{5}{|l|}{ Age Group (years) } \\
\hline $60-69$ & $9(47.4)$ & $101(52.3)$ & 110 & $\chi^{2}=0.171$ \\
\hline$\geq 70$ & $10(52.6)$ & $92(47.7)$ & 102 & $p=0.680$ \\
\hline \multicolumn{5}{|l|}{ Gender } \\
\hline Male & $5(26.3)$ & $78(40.4)$ & 83 & $x^{2}=1.443$ \\
\hline Female & $14(73.7)$ & 115 (59.6) & 129 & $p=0.230$ \\
\hline \multicolumn{5}{|l|}{ Marital Status } \\
\hline Married & $7(36.8)$ & $121(62.7)$ & 128 & $\chi^{2}=4.832$ \\
\hline Not married & $12(63.2)$ & $72(37.7)$ & 84 & $p=0.028$ \\
\hline \multicolumn{5}{|l|}{ Family structure } \\
\hline Monogamous & $7(36.8)$ & $97(50.3)$ & 104 & $\chi^{2}=1.246$ \\
\hline Polygamous & $12(63.2)$ & $96(49.7)$ & 108 & $p=0.264$ \\
\hline \multicolumn{5}{|l|}{ Living condition } \\
\hline Alone & $10(52.6)$ & $31(16.1)$ & 41 & $\chi^{2}=14.829$ \\
\hline With people & $9(47.4)$ & $162(83.9)$ & 171 & $p=0.001$ \\
\hline \multicolumn{5}{|c|}{ Years lived in residence } \\
\hline$\leq 20$ years & $10(52.6)$ & $107(55.4)$ & 117 & $\chi^{2}=0.814$ \\
\hline > 20 years. & $9(47.4)$ & $86(44.6)$ & 95 & $p=0.055$ \\
\hline \multicolumn{5}{|l|}{ Ethnicity } \\
\hline Yoruba & $18(94.7)$ & $183(94.8)$ & 201 & Fisher's $p=1.000$ \\
\hline Others & $1(5.3)$ & $10(5.2)$ & 11 & \\
\hline \multicolumn{5}{|l|}{ Religion } \\
\hline Christianity & 17 (89.5) & $144(74.6)$ & 161 & Fisher's $\mathrm{p}=0.148$ \\
\hline Islam and Others & $2(10.5)$ & 49 (25.4) & 51 & \\
\hline \multicolumn{5}{|l|}{ Level of Education } \\
\hline Not educated & $7(36.8)$ & $73(37.8)$ & 80 & $\chi^{2}=0.007$ \\
\hline Educated & $12(63.2)$ & $120(62.2)$ & 132 & $p=0.933$ \\
\hline \multicolumn{5}{|l|}{ Occupational Status } \\
\hline Unemployed & $7(36.8)$ & $52(26.9)$ & 59 & $\chi^{2}=0.844$ \\
\hline Employed & $12(63.2)$ & $141(73.1)$ & 152 & $p=0.358$ \\
\hline \multicolumn{5}{|l|}{ Housing Unit } \\
\hline Single room & $6(31.6)$ & $32(16.6)$ & 38 & $\chi^{2}=2.645$ \\
\hline $\begin{array}{l}\text { Others (shared flats, } \\
\text { flats or duplexes) }\end{array}$ & $13(68.4)$ & $161(83.4)$ & 174 & $p=0.104$ \\
\hline
\end{tabular}


Table III: Binary logistic regression analysis of factors associated with comorbid depression and anxiety

\begin{tabular}{lllllll}
\hline Variables & $\boldsymbol{B}$ & SE & Wald & $p$-value & OR & $95 \%$ CI \\
\hline $\begin{array}{l}\text { Marital status } \\
\text { Married (Ref) }\end{array}$ & & & & & & \\
Not married & -0.04 & 0.749 & 0.003 & 0.957 & 0.961 & $0.222-$ \\
& & & & & & 4.167 \\
& & & & & & \\
$\begin{array}{l}\text { Living } \\
\text { conditions }\end{array}$ & & & & & & \\
$\begin{array}{l}\text { Living with } \\
\text { family (Ref) }\end{array}$ & & & & & 1 & \\
$\begin{array}{l}\text { Living alone } \\
\text { 1.788 }\end{array}$ & 0.737 & 5.878 & 0.015 & 5.976 & $1.408-$ \\
& & & & & & 25.360 \\
\hline
\end{tabular}

SE - Standard Error; OR - Odd Ratio; CI - Confidence Interval

Although the proportion of the elderly females who had comorbid depression and anxiety was higher than that of males, the findings from the present study concur with the report of no significant association between gender and cooccurring depression and anxiety symptoms among the elderly in the USA. [31] In the present study, marital status was significantly associated with the occurrence of comorbid depression and anxiety among the elderly. The elderly who were widowed/divorced or never married had higher rates of comorbid depression and anxiety than those who were married. This implies that being married or living with people provides some form of social support which may reduce the occurrence of comorbid depression and anxiety among the elderly. This is in agreement with the report of a significant association between marital status and depressive and anxiety symptoms in a study on the co-occurrence of anxiety and depressive disorders in a cohort of older people in England. [32] However, the findings of the present study were in contrast with reports of a lack of significant association between marital status and comorbid depression and anxiety in previous studies conducted among the elderly in Amsterdam and the USA. $[30,31,33]$ Also, living alone among the elderly was significantly associated with comorbid depression and anxiety. Moreover, the odds of having comorbid depression and anxiety for the elderly who lived alone were double the odds of those living with someone. This finding is consistent with the findings reported by Kvaal, et al. [32] Living alone is related to loneliness which is a risk factor for depression and anxiety among older adults. ${ }^{[34]}$ Loneliness is a distressing feeling related to the perception that one's social needs are not fulfilled by the extent of one's social networks. ${ }^{[4]}$ Possible causes of loneliness among Nigerian older adults are the breaking down of the traditional family support systems, bereavements, rural-urban migration as well as international migration of family members. [35]

The conduct of the study in a community which is predominated by one ethnic group in Nigeria may be a limitation to the study because it may not be generalizable to the entire older adult population of Nigeria. Moreover, the nonassessment of the levels of cognitive function of the older adults in the present study may also be a limitation as this makes it impossible to exclude the effect of dementia among the respondents.

\section{Conclusion}

This study provided information on comorbid depression and anxiety among older adults in a Nigerian community. The study also revealed 
that depression and anxiety as well as their comorbidity are highly prevalent among Nigerian older adults and that loneliness is a single factor that predicted older adult comorbid depression and anxiety. Therefore, there is a need for targeted interventions aimed at providing supports for older adults, most especially those who are lonely, widowed, divorced or never being married. Therefore, government agencies, non-governmental agencies, religious organizations and other stakeholders should be involved in developing strategies that will promote social supports and opportunities for social interactions among Nigerian older adults. This, sequentially, may reduce the risk of comorbid depression and anxiety among them. Further research is recommended to establish other determinants of comorbid depression and anxiety among older adults using a longitudinal study design.

Acknowledgement: All the older adults who graciously participated in this study are appreciated; without their generous support and commitment, this research would not have been possible.

Authors Role: AA and AOC conceived the study while OIO and EOA contributed to the study design. AA and AOC did the literature review and analysed the data. OIO and EOA participated in data interpretation. All the authors participated in the drafting of the manuscript. All the authors approved the final version of the manuscript.

Conflict of Interest: None declared.

Funding: Self-funded.

Publication History: Submitted 29 August 2020; Accepted 03 November 2020

\section{References}

1. Naidoo K, van Wyk J. Protocol for a scoping review of age-related health conditions among geriatric populations in sub-Saharan Africa. Syst Rev 2019; 8: 133. doi:10.1186/s13643-019-1055-z.
2. Akosile CO, Mgbeojedo UG, Maruf FA, Okoye EC, Umeonwuka IC, Ogunniyi A. Depression, functional disability and quality of life among Nigerian older adults: prevalences and relationships. Arch Gerontol Geriatr 2018; 74: 39-43. doi:10.1016/j.archger.2017.08.011.

3. Togonu-Bickersteth F, Akinyemi AI. Ageing and national development in Nigeria: Costly assumptions and challenges for the future. Afr Pop Stud 2014; 27: 361-371. https://doi.org/10.11564/27-2-481.

4. Igbokwe CC, Ejeh VJ, Agbaje OS, Umoke PI, Iweama CN, Ozoemena EL. Prevalence of loneliness and association with depressive and anxiety symptoms among retirees in Northcentral Nigeria: a cross-sectional study. BMC Geriatr 2020; 20: 1-10. doi:10.1186/s12877-020-01561-4.

5. National Population Commission. Nigeria Demographic and Health Survey 2008. Abuja, Nigeria: National Population Commission and ICF Macro; 2009. p. 1-629.

6. McCombe G, Fogarty F, Swan D, Hannigan A, Fealy GM, Kyne L, et al. Identified mental disorders in older adults in primary care: A cross-sectional database study. Eur J Gen Pract 2018; 24: 84-91. doi:10.1080/13814788.2017.1402884.

7. Okokon IB, Asibong UE, Ogbonna UK, John EE. Psychogeriatric Problems Seen in the Primary Care Arm of a Tertiary Hospital in Calabar, South-South Nigeria. Int J Geriatr Gerontol 2018; IJGG-107. doi:10.29011/IJGG107.180007.

8. John A, McGregor J, Fone D, Dunstan F, Cornish R, Lyons RA, et al. Case-finding for common mental disorders of anxiety and depression in primary care: an external validation of routinely collected data. BMC Med Informatics Decision Making 2016; 16: 35. doi:10.1186/s12911-016-0274- 
9. Li N, Chen G, Zeng P, Pang J, Gong H, Han Y, et al. Prevalence of depression and its associated factors among Chinese elderly people: A comparison study between community-based population and hospitalized population. Psychiatry Res 2016; 243: 87-91. doi:10.1016/j.psychres.2016.05.030.

10. Pilania M, Bairwa M, Khurana H, Kumar N. Prevalence and Predictors of depression in community-dwelling elderly in rural Haryana, India. Indian J Comm Med 2017; 42: 13-18. doi:10.4103/0970-0218.199792.

11. Manandhar K, Risal A, Shrestha O, Manandhar N, Kunwar D, Koju R, Holen A. Prevalence of geriatric depression in the Kavre district, Nepal: Findings from a crosssectional community survey. BMC Psychiatry 2019; 19: 271. doi:10.1186/s12888-019-2258-5.

12. Thapa SB, Martinez P, Clausen T. Depression and its correlates in South Africa and Ghana among people aged 50 and above: Findings from the WHO Study on Global Ageing and adult health. J Psychiatry 2014;17. doi:10.4172/1994-8220.1000167.

13. Balsamo M, Cataldi F, Carlucci L, Fairfield B. Assessment of anxiety in older adults: a review of self-report measures. Clin Interventions Aging 2018; 13: 573. doi:10.2147/CIA.S114100.

14. Hohls J, Wild B, Heider D, Brenner H, Böhlen $\mathrm{F}$, Saum $\mathrm{K}$, et al. Association of generalized anxiety symptoms and panic with health care costs in older age - Results from the ESTHER cohort study. J Affect Disord 2019; 245: 978986. doi:10.1016/j.jad.2018.11.087.

15. Fiske A, Wetherell JL, Gatz M. Depression in older adults. Ann Rev Clin Psychol 2009; 5: 363-389. doi:10.1146/annurev.clinpsy.032408.153621.

16. Lenze EJ, Mulsant BH, Shear MK, Alexopoulos GS, Frank E, Reynolds CF. Comorbidity of depression and anxiety disorders in later life. Depression Anxiety 2001; 14: 86-93. doi:10.1002/ da.1050.

17. Simning A, Seplaki CL. Association of the cumulative burden of late-life anxiety and depressive symptoms with functional impairment. Int J Geriatr Psychiatry 2020; 35: 80-90. doi:10.1002/gps.5221.

18. Bierman E, Comijs H, Jonker C, Beekman A. Symptoms of anxiety and depression in the course of cognitive decline. Dement Geriatr Cognit Disord 2007; 24: 213-219. doi:10.1159/000107083.

19. Van der Weele GM, Gussekloo J, De Waal MW, De Craen AJ, Van der Mast RC. Cooccurrence of depression and anxiety in elderly subjects aged 90 years and its relationship with functional status, quality of life and mortality. Int J Geriatr Psychiatry 2009; 24: 595-601. doi:10.1002/gps.2162.

20. Hranov LG. Comorbid anxiety and depression: illumination of a controversy. Int J Psychiatry Clin Pract 2007; 11: 171-189. doi:10.1080/13651500601127180.

21. Gureje O, Kola L, Afolabi E. Epidemiology of major depressive disorder in elderly Nigerians in the Ibadan Study of Ageing: a community-based survey. The Lancet. 2007; 370: 957-964. doi:10.1016/S01406736(07)61446-9.

22. Olutoki MO, Olagunju AT, Adeyemi JD. Correlates of depressive illness among the elderly in a mixed urban community in Lagos, Nigeria. Aging Mental Health 2014; 18: 561-569. doi:10.1080/13607863.2013.843156.

23. Yesavage J, Brink T, Rose T, Adey M. The Geriatric Depression Rating Scale: comparison with other self-report and psychiatric rating scales. In: Crook T, Ferris $S$, Bartus E (Editors) Assessment in Geriatric Psychopharmacology. New Canaan, Conn: Mark Powley; 1983. p. 153-167. 
24. Sheikh JI, Yesavage JA. Geriatric Depression Scale (GDS): recent evidence and development of a shorter version. Clinical Gerontologist: The J Aging Mental Health 1986; 5: 165-173..doi:10.1300/J018v05n01_09.

25. Adegunloye OA, Buhari OI, Abiodun OA. Depression in Elderly Primary Health Care Clinic Attendees in Ilorin, Nigeria. Trop J Health Sci 2018;25: 1-7.

26. Onya ON, Stanley PC. Prevalence, presentation and co-morbidity pattern associated with depression among geriatric patients attending the GOPD of UPTH. Int Res J Med Sci 2013; 1: 17-24.

27. Pocklington C, Gilbody S, Manea L, McMillan D. The diagnostic accuracy of brief versions of the Geriatric Depression Scale: a systematic review and meta-analysis. Int J Geriatr Psychiatry 2016; 31: 837-857. doi:10.1002/gps.4407.

28. Spitzer RL, Kroenke K, Williams JB, Löwe B. A brief measure for assessing generalized anxiety disorder: the GAD-7. Arch Intern Med 2006; 166: 1092-1097. doi:10.1001/archinte.166.10.1092.

29. Ayandele O, Popoola OA, Oladiji TO. Addictive use of smartphone, depression and anxiety among female undergraduates in Nigeria: a cross-sectional study. J Health Res 2020; 34: 443-453. doi:10.1108/JHR-10-20190225.

30. Schoevers R, Beekman A, Deeg D, Jonker C, Tilburg Wv. Comorbidity and risk-patterns of depression, generalised anxiety disorder and mixed anxiety-depression in later life: results from the AMSTEL study. Int J Geriatr Psychiatry 2003; 18: 994-1001. doi:10.1002/gps.1001.

31. Simning A, Conwell Y, Fisher SG, Richardson TM, van Wijngaarden E. The characteristics of anxiety and depression symptom severity in older adults living in public housing. Int Psychogeriatr 2012; 24: 614-623. doi:10.1017/S1041610211001979.

32. Kvaal K, McDougall FA, Brayne C, Matthews FE, Dewey ME. Co-occurrence of anxiety and depressive disorders in a community sample of older people: results from the MRC CFAS (Medical Research Council Cognitive Function and Ageing Study). Int J Geriatr Psychiatry 2008; 23: 229-237. doi:10.1002/gps.1867.

33. Vink D, Aartsen MJ, Schoevers RA. Risk factors for anxiety and depression in the elderly: a review. J Affect Disord 2008; 106: 29-44. doi:10.1016/j.jad.2007.06.005.

34. Heikkinen RL, Kauppinen M. Mental wellbeing: A 16-year follow-up among older residents in Jyväskylä. Arch Gerontol Geriatr 2011; 52: 33-39 doi:10.1016/j.archger.2010.01.017.

35. Okoye UO. Family caregiving for ageing parents in Nigeria: Gender differences, cultural imperatives and the role of education. Int J Education Ageing 2012; 2: 139-154. 